\title{
The effects of baths and wet wraps with a sweet whey solution on the level of hydration and barrier function of the epidermis
}

\author{
Daria Sobkowska', Iwona Micek ${ }^{1}$, Maria Urbańska ${ }^{1}$, Agnieszka Seraszek-Jaros ${ }^{1}$, Gerard Nowak ${ }^{1}$, Lucjusz Zaprutko ${ }^{1}$, \\ Rafał Czajkowski', Zygmunt Adamski ${ }^{3}$, Justyna Gornowicz-Porowska ${ }^{1}$ \\ ${ }^{1}$ Department of Practical Cosmetology and Prevention of Skin Diseases, Poznan University of Medical Sciences, Poznan, Poland \\ ${ }^{2}$ Chair of Dermatology, Department of Dermatology and Venereology, Faculty of Medicine, Ludwik Rydygier Medical College \\ in Bydgoszcz, Nicolaus Copernicus University in Torun, Poland \\ ${ }^{3}$ Department of Dermatology, Poznan University of Medical Sciences, Poznan, Poland
}

Adv Dermatol Allergol 2021; XXXVIII (5): 798-803

DOI: https://doi.org/10.5114/ada.2021.110078

\begin{abstract}
Introduction: Sweet whey is known for its various pharmacological uses as an anti-inflammatory and antioxidant agent. This is because whey proteins accelerate the release of bioactive peptides, increase the level of intracellular glutathione and the production of interleukin IL-8. However, the potential skin care effects of whey, especially in its unprocessed state, are still not clear.

Aim: To evaluate in vivo the cosmetic features of sweet whey baths and wet wraps on human skin.

Material and methods: Thirteen healthy Caucasian adult females with no dermatological diseases were examined. We used the Courage-Khazaka MPA-9 device to evaluate the effects of sweet whey baths/wet wraps on skin hydration, transepidermal water loss (TEWL) and melanin and erythema index and pH level in human skin.

Results: It appeared that bathing in the sweet whey solution significantly improved the barrier function of the skin in comparison with tap water treated control area on the face cheek as well as on the forearm by decreasing the value of transepidermal water loss with statistical significance. Skin hydration was enhanced only on the facial skin. No significant differences concerning other parameters were observed.

Conclusions: We showed that sweet whey may have decreased the TEWL level and fixed the barrier function of epidermis in this way. It seems that a bath solution with sweet whey is well tolerated and may promote local blood circulation without affecting the $\mathrm{pH}$ value of the skin.
\end{abstract}

Key words: whey, human skin, hydration, transepidermal water loss.

\section{Introduction}

Whey is a greenish yellow liquid left after milk curdling as a by-product of cheese production. It contains $15-20 \%$ of total milk proteins [1]. These proteins are valued more than casein or soy protein because of their high nutritional quality and fast absorption [2]. Whey protein is composed mainly of $\beta$-lactoglobulin (35-65\%), $\alpha$-lactalbumin (12$25 \%)$, immunoglobulins (8\%), serum albumins (5\%) and lactoferrin (1\%) as stated by Smithers et al. [3, 4]. Some authors emphasize that whey protein is a rich source of branched-chain amino acids (leucine, isoleucine and valine), which play a key role in the regulation of skeletal muscle protein synthesis [5-7]. Moreover, whey proteins reduce oxidative stress and protect from ultraviolet radiation [8]. Anti-inflammation, antioxidant and hepatoprotection are well-known effects of whey protein. As a precursor of the antioxidant glutathione, whey protein decreases effects of stressors. Treatment with whey protein accelerated the release of bioactive peptides, raised the levels of intracellular glutathione and the production of interleukin 8 (IL-8) (this cytokine is believed to mediate pathogenesis of respiratory tract diseases) [9]. Seema carried out a metaanalysis of emerging trends in nutraceutical applications of whey protein and its derivatives [10].

The effects of whey peptides on chronic UVB radiation-induced skin alterations such as thickness, de-

Address for correspondence: Daria Sobkowska, Department of Practical Cosmetology and Prevention of Skin Diseases, Poznan University of Medical Sciences, Poznan, Poland, e-mail: daria.sobkowska@gmail.com Received: 28.03.2020, accepted: 4.05.2020. 
creased suppleness and wrinkle formation were investigated using mouse models. It was documented that the peptides ameliorated photoaging by inhibiting the increase in dermal stiffness, wrinkling and melanin granule formation. The whey peptides decreased the expression of matrix metalloproteinase (MMP-2 and pro-MMP-9) and vascular endothelial growth factor (VEGF). On the other hand, they reduced the number of apoptotic, Ki67-positive and 8-hydroxy-2'-deoxyguanosine (8-OHdG)positive cells induced by chronic UVB radiation. The peptides also prevented type IV collagen [11].

A meta-analysis of systematic review revealed that the incidence of atopic dermatitis was considerably lower among infants in the partially hydrolysed whey-based formula group compared to the bovine milk group [12].

Whey protein has been also demonstrated to reduce postprandial glycaemia by suppression of an appetite, increasing of insulin or incretin hormone secretion and slowing of gastric emptying [13].

It was mentioned that an intake of $20 \mathrm{~g} /$ day of whey protein isolate improved the condition of patients suffering from psoriasis [14].

Since whey is also rich in sulphur-containing amino acids such as cysteine and methionine that provide whey with antioxidant features and cysteine changes into glutathione, a potent intracellular antioxidant, it could be very useful in cosmetology for proper skin care. It suggests that whey peptides could be responsible for nourishing and reducing dehydration of the skin [9].

We distinguish two kinds of whey: acid and sweet. The difference between these two types of whey is that the acid one is characterized by a lower $\mathrm{pH}$ as well as the composition and methods of obtaining [15].

The sweet whey is known for its various pharmacological applications. However, the potential skin care effects of whey, especially in its unprocessed state, are still not clear.

\section{Aim}

The aim of this study was to evaluate the in vivo cosmetic features of sweet whey baths and wet wraps on human skin. The researches included the effect of whey baths and wet wraps on the hydration state of the skin surface, the barrier function of the stratum corneum as well as the $\mathrm{pH}$ level of the skin and the melanin and haemoglobin (erythema) level by reflectance.

\section{Material and methods \\ Examined groups}

For this study, thirteen Caucasian adult females (average age: 39) with healthy skin were treated with sweet whey test bath. The volunteers were in good health and had no dermatological diseases. Prior to the measurements, the volunteers were asked to stay in the test room for at least $15 \mathrm{~min}$ before the measurements so that the skin could acclimatize to room conditions. In order to minimize errors during the research the volunteers were asked not to apply any cosmetic cream in the tested area before the study. Additionally, any sun exposure was forbidden.

The sweet whey was obtained and characterized (Table 1) by the National Association of Dairy Cooperatives in Poland.

\section{Measurements of skin parameters}

Short-term effects of sweet whey baths and wet wraps were investigated on the volar forearm and on the face cheeks of volunteers, respectively. The tested areas $(3 \mathrm{~cm} \times 4 \mathrm{~cm})$ were: the inner surface of the left forearm (bath) as well as the left cheek (wet-wrap) was treated with the sweet whey solution (65 g of sweet whey and $935 \mathrm{~g}$ of water) and the placebo (water) was applied on the inner surface of the right forearm as well as on the right cheek.

All measurements were performed in controlled conditions at a temperature of $22-25^{\circ} \mathrm{C}$ and with an average relative humidity of $50 \%$. Volunteers immersed one forearm for 20 min in a bath solution containing sweet whey at a temperature of $38-42^{\circ} \mathrm{C}$. The second arm was immersed in tap water. Before the study and $2 \mathrm{~h}$ after the bath/wet wrap, the skin parameters were evaluated.

The skin features were measured using non-invasive skin bioengineering techniques. All measurements were performed in duplicate. In vivo techniques for the skin biophysical parameters evaluation were used with the Courage-Khazaka MPA-9 device with probes: Corneometer CM825, Tewameter CM300, Mexameter MX18 and Skin-pH-Meter PH 908 (Courage + Khazaka Electronic, Köln, Germany) to evaluate the effects of the sweet whey bath/wet wrap on skin hydration, transepidermal water loss (TEWL), melanin and erythema index and pH level of human skin.

\section{Statistical analysis}

Statistical analyses were performed using Software Statistica PL 10.0 (StatSoft Inc.). A difference test was used to calculate the significance of percentage occurrence of particular parameters. Statistical analysis was carried out using Wilcoxon test and Mann-Whitney test. A $p<0.05$ was arbitrarily considered statistically significant.

\section{Results}

Sensory evaluation of the sweet whey solution for baths and/or wet wraps demonstrated a yellowishgreenish solution with a neutral smell.

Bathing in the sweet whey solution significantly improved the skin's barrier function in comparison with 
Daria Sobkowska, Iwona Micek, Maria Urbańska, Agnieszka Seraszek-Jaros, Gerard Nowak, Lucjusz Zaprutko, Rafał Czajkowski, Zygmunt Adamski, Justyna Gornowicz-Porowska

Table 1. Characteristics of sweet whey

\begin{tabular}{|c|c|c|c|}
\hline Kind of research & Method & Unit & Result \\
\hline Protein & PB-116 II edition of 30.06 .2018 & $\mathrm{~g} / 100 \mathrm{~g}$ & 12.0 \\
\hline Dietary fibre & AOAC 991.43:1994 & $\mathrm{g} / 100 \mathrm{~g}$ & $<0.5$ \\
\hline Sugars & Enzyme-spectrophotometric method (analysis) & & \\
\hline Glucose & & $\mathrm{g} / 100 \mathrm{~g}$ & $<0.2$ \\
\hline Fructose & & $\mathrm{g} / 100 \mathrm{~g}$ & $<0.2$ \\
\hline Saccharose & & $\mathrm{g} / 100 \mathrm{~g}$ & $<0.2$ \\
\hline Lactose & & $\mathrm{g} / 100 \mathrm{~g}$ & 74.3 \\
\hline Galactose & & $\mathrm{g} / 100 \mathrm{~g}$ & $<0.2$ \\
\hline Amount of all sugars & & $g / 100 \mathrm{~g}$ & 74.3 \\
\hline Ashy material & PB-24 III edition of 04.02 .2009 & $\%$ & 7.7 \\
\hline Fat & PN-EN ISO 1736:2010 & $\mathrm{g} / 100 \mathrm{~g}$ & 0.94 \\
\hline Energy value & $\begin{array}{l}\text { Regulation (EU) No 1169/2011 of the European Parliament and of the Council of } \\
\text { 25.10.2011 }\end{array}$ & & \\
\hline Energy value & & $\mathrm{kcal} / 100 \mathrm{~g}$ & 366 \\
\hline Energy value & & $\mathrm{kJ} / 100 \mathrm{~g}$ & 1555 \\
\hline Carbohydrates & $\begin{array}{l}\text { Regulation (EU) No 1169/2011 of the European Parliament and of the Council of } \\
\text { 25.10.2011 }\end{array}$ & $\mathrm{g} / 100 \mathrm{~g}$ & 77.5 \\
\hline Moistness & PB-23 III edition of 04.02.2009 & $\%$ & 1.85 \\
\hline Vitamin $B_{1}$ & PN-EN 14122:2014-07 & $\mathrm{mg} / 100 \mathrm{~g}$ & 0.27 \\
\hline Vitamin $B_{12}$ & PB-349/LC I edition of 10.05.2017 & $\mu \mathrm{g} / 100 \mathrm{~g}$ & 2.62 \\
\hline Vitamin $B_{2}$ & PN-EN 14152:2014-07 & $\mathrm{mg} / 100 \mathrm{~g}$ & 3.00 \\
\hline Vitamin $\mathrm{B}_{6}$ & PN-EN 14164:2014-08 & $\mathrm{mg} / 100 \mathrm{~g}$ & 0.25 \\
\hline $\begin{array}{l}\text { Amount of saturated } \\
\text { fatty acids (SAFA) }\end{array}$ & $\begin{array}{l}\text { PN-EN ISO 12966-1:2015-01. PN-EN ISO 12966-2:2017-05 except p.5.3 i 5.5, PN-EN ISO } \\
\text { 12966-4:2015-07 }\end{array}$ & $\mathrm{g} / 100 \mathrm{~g}$ & 0.6 \\
\hline Zinc & PB-223/ICP, II edition of 12.01 .2015 & $\mathrm{mg} / 100 \mathrm{~g}$ & 0.33 \\
\hline Phosphorus & PB-223/ICP, II edition of 12.01 .2015 & $\mathrm{mg} / 100 \mathrm{~g}$ & 584 \\
\hline Magnesium & PB-223/ICP, II edition of 12.01 .2015 & $\mathrm{mg} / 100 \mathrm{~g}$ & 119 \\
\hline Potassium & PB-223/ICP, II edition of 12.01 .2015 & $\mathrm{mg} / 100 \mathrm{~g}$ & 2518 \\
\hline Sodium & PB-223/ICP, II edition of 12.01.2015 & $g / 100 \mathrm{~g}$ & 0.73 \\
\hline $\mathrm{NaCl}(\mathrm{Nax} 2,5)$ & from calculation & $\mathrm{g} / 100 \mathrm{~g}$ & 1.82 \\
\hline Calcium & PB-223/ICP, II edition of 12.01 .2015 & $\mathrm{mg} / 100 \mathrm{~g}$ & 630 \\
\hline
\end{tabular}

Table 2. The results of percentage distribution of the hydration and TEWL levels in the examined group (sweet whey solution versus placebo)

\begin{tabular}{llccc}
\hline Variable & & Sweet whey solution $(n=13)$ & Placebo water $(n=13)$ & $P$-value \\
\hline \multirow{2}{*}{ Face cheeks } & TEWL $\downarrow$ & $8 / 13(61.5 \%)$ & $2 / 13(15.4 \%)$ & $0.0157^{\mathrm{a}}$ \\
\cline { 2 - 5 } & Hydration $\uparrow$ & $10 / 13(76.9 \%)$ & $2 / 13(15.4 \%)$ & $0.0017^{\mathrm{a}}$ \\
\hline \multirow{2}{*}{ Forearms } & TEWL $\downarrow$ & $10 / 13(76.9 \%)$ & $2 / 13(15.4 \%)$ & $0.0017^{\mathrm{a}}$ \\
\cline { 2 - 5 } & Hydration $\uparrow$ & $8 / 13(61.5 \%)$ & $4 / 13(30.8 \%)$ & $0.1164^{\mathrm{b}}$ \\
\hline
\end{tabular}

$n$-number of volunteers, ${ }^{a}$ statistically significant, ${ }^{b}$ statistically insignificant.

the tap water treated control area on the face cheek as well as on the forearm by decreasing the value of transepidermal water loss with statistical significance ( $p=$ 0.0157 and $p=0.0017$, respectively).
Skin hydration was enhanced on the face cheek treated with the sweet whey solution in the examined group ( $p=0.0017$ ), which means that the treatment moisturized facial skin. However, no statistical significant 
improvement in the skin hydration of the forearm was revealed $(p>0.05)$.

The results of percentage distribution of the hydration and TEWL levels in the examined group are shown in Table 2.

Detailed results of the skin's biophysical parameters before and after the treatment with sweet whey are presented in Table 3.

Analysing skin colour we reported a statistically significant elevated level of erythema in the sweet whey solution group versus the placebo-water group after the treatment on the forearm $(p=0.0286)$. No significant difference in the erythema index of the examined groups was found for the face after treatment ( $p$ > 0.05).

No statistical significant differences were reported in the $\mathrm{pH}$ value of examined and control groups, both for the forearm and for the face $(p>0.05)$.

The procedure of the sweet whey bath and the wet wrap of representative volunteers is presented in Figure 1.

\section{Discussion}

In various skin care products, whey protein is present as: whey protein concentrate, whey protein isolate or hydrolysed whey protein. They are produced using special methods: precipitation, filtration, dialysis and ion exchange. After removing non-protein constituents from whey the finished dry product contains not less than $25 \%$ protein for whey protein concentrate, and not less than $90 \%$ protein for whey protein isolate. While hydrolysed whey protein obtained after treatment with mild acids and warm temperatures contains about $90-95 \%$ protein. In cosmetics whey protein is mainly used as a skin and hair conditioning agent. It is believed that components in cow's milk whey are similar to the natural moisturizing factor (NMF) found in human skin. The NMF is a group of substances such as amino acids, peptides, PCA, lactates, salts, sugars and urea. All of these ingredients are responsible for keeping the skin's surface intact, supple and hydrated. As we get older, the contents of NMF in the skin decrease. That is why we observe dry and rough skin. Due to the fact that whey protein is similar to NMF, it is expected that application of this ingredient may rebuild the NMF and improve the moisture level of the skin [16].

However, cosmetic products and expertise present on the market concern only processed whey in specific formulations. In light of this, to the best of our knowledge, there are no observations about the direct role of unprocessed whey in baths and/or wet wraps on human skin.

We have assessed the possible extent of damage to the epidermal barrier by determining TEWL, which is a commonly accepted sensitive indicator of disruptions in the epidermal lipid barrier. The results revealed that formulations containing sweet whey may have significantly decreased the TEWL level and in this way fixed the barrier function of epidermis.

It is known that retention of water in the stratum corneum plays an important role in the regulation of skin functions. Loss of water may disturb the skin's appearance and lead to various skin disorders. Our results indicated that the cosmetics application of sweet whey on the face kept higher water content and a lower transepidermal water loss at the

Table 3. Detailed results of the skin's biophysical parameters comparison before and after the treatment with a sweet whey solution

\begin{tabular}{lccc}
\hline Location & Parameter & $\begin{array}{c}\text { Before treatment } \\
\text { Mean } \pm \text { SD }\end{array}$ & $\begin{array}{c}\text { After treatment } \\
\text { Mean } \pm \text { SD }\end{array}$ \\
\hline $\begin{array}{l}\text { Face } \\
\text { cheek } \\
(n=13)\end{array}$ & TEWL & $13.60 \pm 5.3$ & $12.00 \pm 4.6$ \\
\cline { 2 - 4 } & Hydration & $51.67 \pm 8.4$ & $57.15 \pm 9.7$ \\
\cline { 2 - 4 } & Erythema & $372.31 \pm 48.7$ & $385.78 \pm 70$ \\
\cline { 2 - 4 } & $\mathrm{pH}$ & $5.33 \pm 0.42$ & $5.40 \pm 0.7$ \\
\hline $\begin{array}{l}\text { Forearm } \\
(n=13)\end{array}$ & TEWL & $8.99 \pm 4$ & $6.79 \pm 1.9$ \\
\cline { 2 - 4 } & Hydration & $47 \pm 13$ & $49 \pm 15$ \\
\cline { 2 - 4 } & Erythema & $180.69 \pm 38$ & $182.79 \pm 37$ \\
\cline { 2 - 4 } & $\mathrm{pH}$ & $5.16 \pm 0.5$ & $5.90 \pm 0.43$ \\
\hline
\end{tabular}

$n$-number of volunteers, SD - standard deviation.
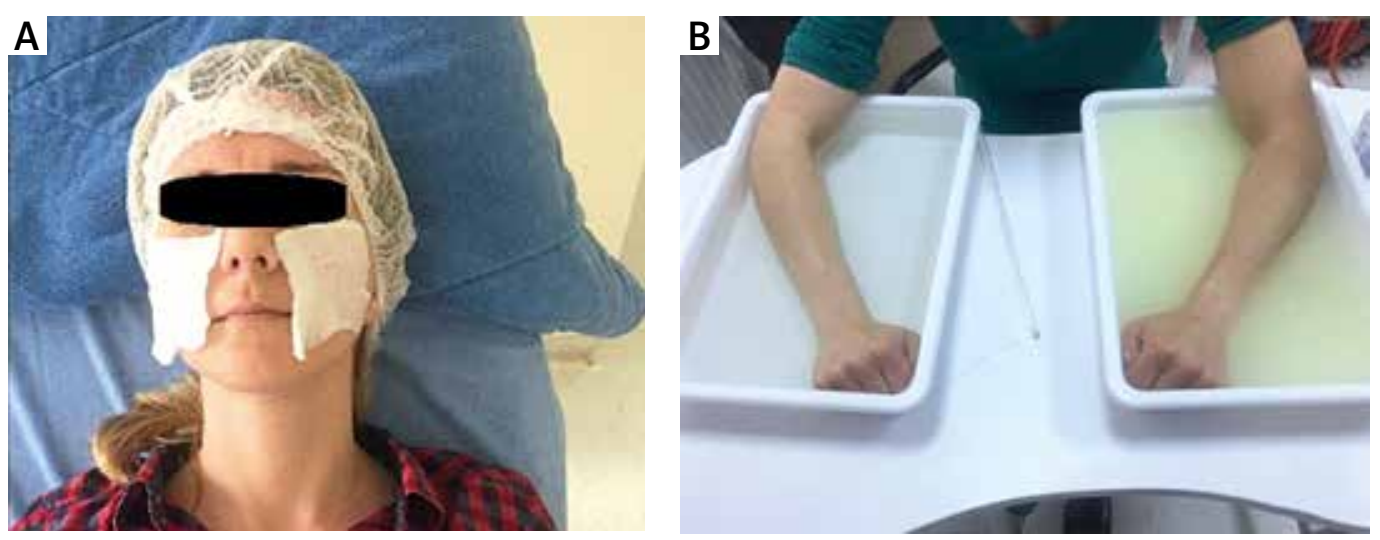

Figure 1. The procedure of wet-wrap with the sweet whey solution (A) and bath with the sweet whey solution (B) of the representative volunteer 
same time. Thus, wet wraps containing sweet whey have moisturizing effects on the facial skin.

A lot of data indicated that human skin colour varies slightly depending on blood circulation. This probably local and transitional increase in skin erythema (redness) after whey treatment may be a result of the improvement of dermal blood circulation rather than the manifestation of cutaneous inflammation.

We found no differences in the $\mathrm{pH}$ value between groups. The cosmetics with sweet whey probably do not affect the physiological pH value of human skin. It is known that the $\mathrm{pH}$ level in the stratum corneum is increased in inflamed skin; therefore, the lack of tendency to increase the $\mathrm{pH}$ level is important to the protective functions of the skin.

Whey protein contains amino acid cysteine, which is a building block for the antioxidant, for example glutathione. This substance is responsible for removing free radicals. It is known that free radicals contribute to the formation of the first signs of aging, premature wrinkles. Factors such as stress, toxin exposure and aging cause the level of glutathione in the skin to decrease. That is why using whey protein (which stimulates the production of glutathione) can improve the antioxidant features of the skin $[9,17,18]$. Except for vitamins $B_{1}, B_{6}$ and $B_{12}$, whey also contains whey protein, calcium, potassium, phosphorus, iodine and other minerals. Additionally, whey's lactic acid has a peeling effect. Whey proteins can also stimulate cell division [19].

Recent data indicated that dairy products may enhance wound healing as well as may improve the surface roughness, depigmentation and mild wrinkling of the skin [20-22]. The efficacy is related with the presence of bioactive ingredients (e.g. acetic acid and lactic acid produced by the bacteria). Probably, anti-inflammatory action of these ingredients enables the process of re-epithelialization [21]. It should be noted that the existing studies on the effects of the topical application of dairy products are limited and further investigations are needed to examine the mechanism involved.

Our studies revealed that whey proteins could be the basis for facial creams because they keep proper moisture levels and decrease the level of the dehydration of the skin. It is necessary to provide more research, which will confirm or not the positive effects of whey proteins on human skin.

In conclusion, our data demonstrated that sweet whey is effective in increasing skin hydration and decreasing the TEWL values, especially on the face, indicating the potential skin care effects of sweet whey.

\section{Conclusions}

Our findings demonstrated that bathing in the sweet whey solution was well tolerated, improved skin barrier function and enhanced the stratum corneum hydration.
It seems that bath with the sweet whey solution may promote local blood circulation without affecting the $\mathrm{pH}$ level of the skin.

\section{Conflict of interest}

The authors declare no conflict of interest.

\section{References}

1. Yalçin AS. Emerging therapeutic potential of whey proteins and peptides. Curr Pharm Des 2006; 12: 1637-43.

2. Sindayikengera S, Xia W. Nutritional evaluation of caseins and whey proteins and their hydrolysates from protamex. J Zhejiang Univ Sci B 2006; 7: 90-8.

3. Smithers GW, Ballard FJ, Copeland AD, et al. New opportunities from the isolation and utilization of whey proteins. J Dairy Sci 1996; 79: 1454-9.

4. Ha HK, Rankin SA, Lee MR, et al. Development and characterization of whey protein-based nano-delivery systems: a review. Molecules 2019; 24: 3254.

5. Bounous G, Gervais F, Amer V, et al. The influence of dietary whey protein on tissue glutathione and the diseases of aging. Clin Invest Med 1989; 12: 343-9.

6. Hulmi JJ, Lockwood CM, Stout JR. Effect of protein/essential amino acids and resistance training on skeletal muscle hypertrophy: a case for whey protein. Nutr Metab 2010; 7: 51.

7. Chen WC, Huang WC, Chiu CC, et al. Whey protein improves exercise performance and biochemical profiles in trained mice. Med Sci Sports Exerc 2014; 46: 1517-24.

8. Sousa GTD, Lira FS, Rosa JC, et al. Dietary whey protein lessens several risk factors for metabolic diseases: a review. Lipids Health Dis 2012; 11: 67.

9. Piccolomini AF, Iskandar MM, Lands LC, et al. High hydrostatic pressure pre-treatment of whey proteins enhances whey protein hydrolysate inhibition of oxidative stress and IL-8 secretion in intestinal epithelial cells. Food Nutr Res 2012; 56. doi: 10.3402/fnr.v56i0.17549.

10. Seema P. Emerging trends in nutraceutical applications of whey protein and its derivatives. J Food Sci Technol 2015; 52: 6847-58.

11. Kimura Y, Sumiyoshi M, Kobayashi T. Whey peptides prevent chronic ultraviolet B radiation-induced skin aging in melanin-possessing male hairless mice. J Nutr 2014; 144: 27-32.

12. Alexander DD, Schmitt DF, Tran NL, et al. Partially hydrolyzed $100 \%$ whey protein infant formula and atopic dermatitis risk reduction: a systematic review of the literature. Nutr Rev 2010; 68: 232-45.

13. Mignone LE, Wu T, Horowitz M, et al. Whey protein: the "whey" forward for treatment of type 2 diabetes? World J Diabetes 2015; 6: 1274-84.

14. Prussick R, Prussick L, Gutman J. Psoriasis improvement in patients using glutathione-enhancing, nondenatured whey protein isolate: a pilot study. J Clin Aesthet Dermatol 2013; 6: 23-6.

15. Teixeira FJ, Santos HO, Howell SL, et al. Whey protein in cancer therapy: a narrative review. Pharmacol Res 2019; 144: 245-56.

16. Kezic S, Kammeyer A, Calkoen F, et al. Natural moisturizing factor components in the stratum corneum as biomarkers of filaggrin genotype: evaluation of minimally invasive methods. Br J Dermatol 2009; 161: 1098-104. 
17. Flaim C, Kob M, Di Pierro AM, et al. Effects of a whey protein supplementation on oxidative stress, body composition and glucose metabolism among overweight people affected by diabetes mellitus or impaired fasting glucose: a pilot study. J Nutr Biochem 2017; 50: 95-102.

18. Hewitt E, Mros S, McConnell M, et al. Melt-electrowriting with novel milk protein/PCL biomaterials for skin regeneration. Biomed Mater 2019; 14: 055013.

19. Gillespie AL, Calderwood D, Hobson L, et al. Whey proteins have beneficial effects on intestinal enteroendocrine cells stimulating cell growth and increasing the production and secretion of incretin hormones. Foog Chem 2015; 189: 120-8.

20. Farag MA, Jomaa SA, El-Wahed AA, et al. The many faces of kefir fermented dairy products: quality characteristics, flavour chemistry, nutritional value, health benefits, and safety. Nutrients 2020; 12: E346.

21. Barzegari AA, Hashemzaei M, Majdani R, et al. Effects of topical treatment of second-degree burn wounds with Lactobacillus acidophilus on the wound healing process in male rats. Pharm Biomed Res 2018; 3: 23-30.

22. Huang HC, Lee IJ, Huang C, et al. Lactic acid bacteria and lactic acid for skin health and to inhibit melanogenesis. Curr Pharm Biotechnol 2020; 21: 566-77. 